\title{
Sofrimento psíquico em policiais civis do Estado do Rio de Janeiro
}

\author{
Psychic suffering among civil police officers in Rio de Janeiro State
}

Liana Wernersbach Pinto ${ }^{1}$

Ana Elisa Bastos Figueiredo ${ }^{1}$

Edinilsa Ramos de Souza ${ }^{1}$

${ }^{1}$ Centro Latino-Americano de Estudos de Violência e

Saúde Jorge Careli, Escola Nacional de Saúde Pública, Fundação Oswaldo Cruz. Av. Brasil 4036/700,

Manguinhos. 21040-361

Rio de Janeiro RJ.

lianawp@fiocruz.br
Abstract The paper discusses the relationship between work and psychic suffering among police officers in the State of Rio de Janeiro. A questionnaire was filled out by these professionals in three separate studies: Capital Baixada Fluminense and Interior. The socio-demographic profile, quality of life, health and working conditions were investigated. Psychic suffering was measured by the SRQ-20. A logistic regression model was used to identify factors associated with psychic suffering. The results showed it to be associated with the following variables: level of satisfaction with the ability to react to difficult situations; performing the work for which the officers were trained; suffering some victimization; unit location; problems in the nervous system; and degree of satisfaction with life in general. Those who reported problems in the nervous system and victimization showed an OR of 7.25 and 3.08, respectively. The professionals who considered themselves dissatisfied or very dissatisfied with the ability to react to difficult situations and life in general showed an OR of 10.85 and 6.69, respectively, compared with those who considered themselves satisfied or very satisfied. Professionals from the Baixada showed an increased risk of psychic suffering compared to a reduced risk among those from the Interior.

Key words Violence, Police, Psychic suffering, Work, Mental health.
Resumo O artigo trata da relação entre trabalho e sofrimento psíquico em policiais civis do Estado do Rio de Janeiro. Os dados foram obtidos a partir de questionário autopreenchido aplicado a esses profissionais em três estudos distintos: Capital, Baixada Fluminense e Interior. Foram pesquisadas questões relativas ao perfil dos policiais, qualidade de vida, condições de saúde e de trabalho. $O$ sofrimento psíquico foi aferido pela SRQ-20. Utilizou-se um modelo de regressão logística para verificar os fatores associados ao sofrimento psíquico. Mostraram-se associadas as seguintes variáveis: grau de satisfação com a capacidade de reagir a situações difíceis, exercer o trabalho para o qual foi treinado, ter sofrido alguma vitimização, a área de localização da unidade (Capital, Interior, Baixada), problemas de sistema nervoso e o grau de satisfação com a vida como um todo. Os que mencionaram problemas do sistema nervoso e vitimização apresentaram OR de 7,25 e 3,08, respectivamente. Quanto ao grau de satisfação com capacidade de reagir a situações difíceis e com a vida como um todo, os profissionais que se declararam insatisfeitos ou muito insatisfeitos apresentaram, respectivamente, OR 10,85 e 6,69 quando comparados com aqueles que se consideravam satisfeitos ou muito satisfeitos. Os profissionais da Baixada apresentam risco de sofrimento psíquico aumentado e os do Interior, diminuído. Palavras-chave Violência, Polícia, Sofrimento Psíquico, Trabalho, Saúde Mental 


\section{Introdução}

Este trabalho apresenta uma análise dos fatores associados ao sofrimento psíquico de policiais civis do Estado do Rio de Janeiro. É resultado de pesquisas realizadas no Centro Latino Americano de Estudos sobre Violência, da Fundação Oswaldo Cruz, onde se percebeu a existência de relações entre as condições de trabalho e desgastes na saúde física e mental do policial.

Segundo Bertão e Hashimoto o o "trabalho pode ser uma forma de obter satisfação, quando permite que o indivíduo mantenha sua história pessoal articulada com a realidade social. Mas o trabalho não elimina por completo os sofrimentos advindos da inserção no mundo civilizado". Pois, no mundo do trabalho, transitam desejos e frustrações que podem se sobrepor e gerar tensões resultantes da intensidade com que são vividos e da distância entre aquilo que é idealizado e o que é vivenciado. Freud² afirma que "há sempre uma sensação de triunfo quando algo no ego coincide com o ego ideal", e a possibilidade de estabelecer um vínculo positivo entre o ego ideal e o ego real permite vincular o trabalho como estruturante dos processos identitários que configuram a noção de sujeito-trabalhador ${ }^{3}$. Mas esta pode ser adulterada, face ao modo como afeta o trabalhador de forma negativa ${ }^{4}$.

$\mathrm{Na}$ concepção de Mendes ${ }^{5}$ a organização do trabalho se caracteriza como "processo subjetivo no qual se encontram envolvidos diferentes sujeitos em interação com uma dada realidade, resultando em uma dinâmica própria às situações de trabalho enquanto lugar de produção de significações psíquicas e de construção de relações sociais". Assim, a organização do trabalho constitui-se de aspectos materiais, como os instrumentos para a operacionalização das tarefas e de aspectos simbólicos que dão significado ao trabalho e estão relacionados principalmente às dificuldades ou facilidades na realização da tarefa, ao seu significado enquanto tarefa concluída em relação à ascensão profissional, ao estatuto social do trabalhador.

O sofrimento psíquico caracteriza-se como um conceito amplo, multidimensional, implicando numa carga psíquica compreendida como as exigências relacionadas à organização do trabalho, à frequência de situações emergenciais, ao ritmo imposto no desenvolvimento das atividades, ao grau de automatização e monotonia das tarefas, ao tempo disponível, ao grau de responsabilidade na resolutividade das situações emergentes, além dos recursos que no processo de trabalho interagem dinamicamente entre si e a subjetividade e o corpo do trabalhador proporcionando processos adaptativos que redundam em desgaste, e perda da capacidade corporal e psíquica $^{6,7}$.

$\mathrm{Na}$ inter-relação entre trabalho e sofrimento psíquico, a organização dos processos de trabalho é compreendida como divisão das tarefas, hierarquia, repartição das atividades e comando, que podem trazer implicações para a saúde do trabalhador, tanto sob a forma de bem-estar como de manifestações de sintomas de sofrimento psíquico, pois quanto mais controladora e rígida for essa organização, mais ela afeta a vida do trabalhador ${ }^{8,9}$ ao aumentar a repressão e diminuir o sentimento de liberdade e criatividade originário da execução das tarefas.

Os estudos de Derriennic ${ }^{10}$, Périleux ${ }^{11}$, Mendes $^{12}$, Dejours ${ }^{13}$ e Morrone ${ }^{14}$, estabelecem indicadores que revelam a vivência de sofrimento no trabalho: sentimentos de solidão e cansaço, condutas de inibição, propensão à agressividade, sentimento de medo, ansiedade, tédio e insatisfação com o trabalho, sentimento de desgaste, condutas de obediência, isolamento e submissão, sentimento de desgosto e insegurança.

Este estudo se detém no trabalho do policial civil cujo principal desfecho é a produção do inquérito policial. Segundo Minayo e Souza ${ }^{15}$, “o Código de Processo Penal não determina as formas de estruturação das atividades. Cabe à própria instituição a organização da estrutura, do funcionamento e do estabelecimento das mediações necessárias ao cumprimento das tarefas de investigação e produção do inquérito".

O estudo de Lima ${ }^{16}$ sobre o papel institucional da polícia no sistema judiciário identifica que esse papel está intimamente relacionado e sofre as influências da posição que a Polícia ocupa nesse sistema. Lima informa ainda que os procedimentos criminais que produzem a verdade do fato delituoso não surgem de uma mediação que resulte na resolução de conflitos e produção de novos contratos de "ordenamento social", mas estão fundados na descoberta da verdade. Cabe à autoridade policial descobrir a verdade além de qualquer dúvida, expressa na confissão. Entretanto, não raras vezes tais descobertas, validadas pela forma da inquirição com que foi obtida, são derrubadas quando submetidas aos critérios do processo judicial.

O objetivo deste artigo é investigar os fatores associados ao sofrimento psíquico de policiais civis que atuam em distintas áreas do Estado do Rio de Janeiro - Capital, Baixada Fluminense e Interior. Entende-se que embora haja semelhanças na estrutura e no processo de trabalho poli- 
cial nestas áreas, também existem especificidades que contribuem para distintos desgastes e produção de sofrimento.

\section{Metodologia}

Este trabalho reanalisa dados oriundos de três pesquisas de corte transversal desenvolvidas pelo Centro Latino-Americano de Estudos de Violência e Saúde Jorge Careli/Claves, da Fundação Oswaldo Cruz/Fiocruz, que estudaram as condições de trabalho, saúde e qualidade de vida de policiais civis do Estado Rio de Janeiro ${ }^{15,17,18}$. Essas pesquisas foram realizadas em momentos distintos, mas usaram a mesma metodologia de triangulação de métodos ${ }^{19}$, com abordagens qualitativa (entrevistas e grupos focais) e quantitativa (aplicação de questionário) adaptadas para cada área estudada. Neste artigo analisam-se apenas os dados provenientes do questionário.

A Polícia Civil contava à época dos estudos com 40 delegacias na Capital do Estado, 18 na Baixada Fluminense e 78 no Interior. Dessas, foram estudadas 39 na Capital, 19 na Baixada (18 delegacias mais uma especializada) e 6 no Interior.

No estudo da Capital adotou-se uma amostra aleatória por conglomerados em um estágio, cujos detalhes podem ser encontrados em Minayo e Souza ${ }^{15}$. Nessa pesquisa os policiais foram divididos em estratos, segundo a natureza do serviço - administrativo, técnico e operacional - e os cargos. A título de comparabilidade foram analisados neste artigo apenas os dados referentes aos 533 questionários respondidos por policiais de estrato operacional da Capital (aqueles que atuam nas delegacias de polícia) dos 732 policiais do estrato $(27,2 \%$ de perdas), lotados em 18 Delegacias de Polícia.

Em relação à Polícia do Interior, trabalhou-se com cinco municípios e seis Delegacias de Polícia/ DP: Angra dos Reis (Região da Baía de Ilha Grande, $8^{\circ}$ CRPI e $166^{a}$ DP), Araruama (Região da Baixada Litorânea, 2 CRPI e 118 a DP), Barra do Piraí (Região do Médio Paraíba, 10 CRPI e 88 DP), Campos dos Goytacazes (Região Norte Fluminense, $4^{\circ} \mathrm{CRPI}$ e $134^{\mathrm{a}} \mathrm{DP}$ e $\left.146^{\mathrm{a}} \mathrm{DP}\right)$ e Itaperuna (Região Noroeste Fluminense, 5 CRPI e 143a DP). Foram analisados dados de 159 questionários (19,9\% de perda) de policiais do Interior.

Para o estudo da Baixada Fluminense foram incluídas todas as delegacias da área, situadas nos municípios de: Belford Roxo, Duque de Caxias, Itaguaí, Japeri, Magé, Mesquita, Nilópolis, Nova Iguaçu, Queimados, São João de Meriti e Seropédica. Também foi inserida no estudo a
Delegacia Especializada de Homicídios da área. Dos cerca de 514 policiais lotados na área, 222 $(43,2 \%)$ responderam ao questionário.

O questionário autopreenchido era composto por quatro blocos contendo: (1) informações gerais sobre ocupação, moradia, rendimentos, gastos e outros dados pessoais; (2) perguntas referentes à qualidade de vida; (3) questões sobre condições de trabalho e (4) condições de saúde. Pequenas adaptações foram feitas nesse instrumento para sua aplicação em cada uma das áreas estudadas, a fim de ajustá-lo à realidade e incorporar as especificidades locais.

A coleta foi feita ora distribuindo-se diretamente o questionário ao policial ora entregando-o a um responsável por sua distribuição na unidade.

Para os objetivos deste artigo foram analisadas 157 questões de cada um dos questionários, dentre as quais estão incluídas três escalas:

Self Report Questionnarire (SRQ-20): Por meio desta escala, desenvolvida por Harding et al. ${ }^{20}$, mensurou-se o sofrimento psíquico dos policiais. Este instrumento afere a existência de distúrbios psiquiátricos menores, sendo constituída por 24 perguntas, das quais 20 são sobre distúrbios não psicóticos (sofrimento psíquico) e quatro se referem a distúrbios psicóticos. Cada resposta positiva corresponde a um ponto. Utiliza-se o valor 7 como ponto de corte para homens e o valor 8, para as mulheres. A versão aplicada foi validada para a população brasileira por Mari e Williams ${ }^{21}$ para a qual se observou sensibilidade de $83 \%$, especificidade de $80 \%$ e $19 \%$ de erros de classificação.

Escala de Apoio Social: desenvolvida por Sherbourne e Stewart ${ }^{22}$ e validada por Chor et al. ${ }^{23}$, possui 19 itens relativos ao apoio social e cinco de rede social. Neste trabalho, apenas os itens referentes ao apoio social foram utilizados. Essa escala é constituída por cinco dimensões: (1) emocional (alguém em quem confiar, disponível para ouvir, compartilhar preocupações etc); (2) de informação (ter alguém que dê sugestões, bons conselhos etc); (3) material (receber ajuda se ficar de cama, para levar ao médico, preparar refeições e ajudar nas tarefas diárias, caso adoeça); (4) afetiva (ter alguém que demonstre afeto e amor etc.); e (5) de interação positiva (divertirse com outros, capacidade de relaxar, de fazer coisas agradáveis e de distrair-se). São obtidos cinco escores, um para cada dimensão. As opções de resposta são: nunca, raramente, às vezes, quase sempre, sempre.

Escala Job Stress Scale (Demanda e controle): desenvolvida por Karasek e Theorell ${ }^{24}$ na década 
de 70, avalia o estresse no trabalho como fruto da interação entre as demandas e o controle que o trabalhador possui sobre o processo de trabalho. As ocupações foram classificadas em dois eixos e quatro quadrantes ou possibilidades: (1) trabalhos com alto desgaste (maior demanda e menor controle - job strain); (2) trabalhos mais ativos (maior demanda e controle); (3) trabalhos de menor desgaste (menor demanda e maior controle - situação "ideal”); e (4) trabalhos mais passivos (menor controle e demanda) ${ }^{25,26}$. Uma versão resumida da escala foi adaptada para o português por Alves et al. ${ }^{26}$.

Para as análises foram empregados dados referentes a 914 policiais civis (533 da Capital, 159 do Interior e 222 da Baixada). O processamento dos dados foi realizado no programa Epidata versão 3.1. e as análises foram feitas no software Statistical Software for Social Sciences/SPSS versão 19.0 .

Inicialmente, foram realizadas análises descritivas das frequências das variáveis e análises bivariadas. A seguir, foi ajustado um modelo de regressão logística hierarquizado ${ }^{27}$ para a identificação de fatores associados ao sofrimento psíquico. A escolha das variáveis utilizadas no modelo baseou-se em estudo prévio realizado ${ }^{28}$. Primeiro foram inseridas as variáveis do nível distal (perfil socioeconômico e demográfico do policial), depois as do nível intermediário (qualidade de vida e condições de saúde) e finalmente, as variáveis do nível proximal (condições de trabalho). Entende-se que as variáveis de cada um desses níveis tem um efeito sobre os sucessivos níveis da cadeia hierárquica do sofrimento psíquico. As variáveis significativas ( $\mathrm{p}$-valor no teste de Wald menor ou igual a 0,05 ) em um passo foram inseridas na etapa seguinte da modelagem, seguindo-se a orientação dos níveis hierárquicos.

Os três estudos dos quais se originam os dados aqui analisados foram submetidos e aprovados pelo Comitê de Ética em Pesquisa da Escola Nacional de Saúde Pública, conforme a resolução do Conselho Nacional de Saúde.

\section{Resultados}

Na Tabela 1 é possível ver um perfil demográfico e socioeconômico dos policiais civis do estado do Rio de Janeiro de acordo com as áreas estudadas. Nela, verifica-se que a maioria dos policiais civis entrevistados é branca $(62,6 \%)$, do sexo masculino $(86,4 \%)$, casada $(75,1 \%)$ e está com 36 anos ou mais $(83,3 \%)$. Quanto à escolaridade, observa-se que $53,4 \%$ dos pesquisados têm o nível superior completo. Em relação à renda, $76,5 \%$ deles possuem rendimentos na faixa de $\mathrm{R} \$ 1.001,00$ a R $\$ 2.500,00$.

$\mathrm{Na}$ Tabela 2 observam-se as condições de trabalho dos policiais civis do Estado do Rio de Janeiro. Verifica-se que $74,3 \%$ atuam na polícia há mais de 10 anos. Em torno de 63\% consideraram que sua vida melhorou após entrar na Polícia Civil contra $12,5 \%$ que acharam que houve piora. Observase que $60,8 \%$ afirmaram trabalhar muitas vezes além do horário. Cerca de $47 \%$ informaram exercer outra atividade fora da Polícia. Para 23,3\% dos policiais entrevistados a atividade profissional é exercida no mesmo local em que mora.

Ainda da Tabela 2 encontra-se o resultado oriundo da aplicação da escala de estresse ocupacional. Pode-se verificar que $49,9 \%$ dos policiais foram classificados na condição de ativos, ou seja, seu trabalho caracteriza-se por grande demanda, mas eles têm controle sobre as atividades desenvolvidas. Aproximadamente $20 \%$ dos profissionais entrevistados foram classificados como possuindo trabalho com alto desgaste (alta demanda e baixo controle), significando situação de estresse.

Quanto à percepção de risco, mais de 94\% dos trabalhadores afirmaram já ter passado por situações em que se consideraram sob risco. No entanto, apenas $17,2 \%$ relataram ter sido vítima de alguma agressão (Tabela 2).

$\mathrm{Na}$ Tabela 3 verifica-se presença importante de problemas de saúde referidos pelos policiais entrevistados. Mais de 60\% informaram ter problemas nos ossos, pele e músculos e problemas de visão, audição e fala. Cerca de 33\% relataram ter colesterol alto, $37,1 \%$ afirmaram ter problemas digestivos e $37,9 \%$, no sistema nervoso. $\mathrm{O}$ consumo de substâncias foi relatado por $17,5 \%$ dos policiais.

Em relação à prática de esportes, 39,0\% dos policiais relataram essa prática pelo menos uma vez por semana. Mas é alta a proporção $(42,4 \%)$ dos que declararam não praticar nenhum esporte (Tabela 3).

Verificou-se a presença de sofrimento psíquico (segundo a SRQ-20) em 21,0\% no conjunto dos policiais civis.

Em relação à qualidade de vida, observou-se que $85,4 \%$ dos policiais se mostraram muito satisfeitos ou satisfeitos com sua capacidade de reagir a situações difíceis. Quanto ao grau de satisfação com a vida como um todo se observou um percentual de $77,7 \%$ de indivíduos muito satisfeitos ou satisfeitos (Tabela 3).

Quanto ao apoio social, observam-se percentuais acima de $50 \%$ para a categoria “alto" em todas as dimensões da escala. Chamam atenção 
Tabela 1. Perfil demográfico e socioeconômico dos policiais civis do Estado do Rio de Janeiro, segundo localização da unidade (Capital, Interior e Baixada).

\begin{tabular}{|c|c|c|c|c|c|c|c|c|}
\hline \multirow{2}{*}{ Característica } & \multicolumn{2}{|c|}{ Capital } & \multicolumn{2}{|c|}{ Interior } & \multicolumn{2}{|c|}{ Baixada } & \multicolumn{2}{|c|}{ Total } \\
\hline & $\mathrm{N}$ & $\%$ & $\mathbf{N}$ & $\%$ & $\mathbf{N}$ & $\%$ & $\mathbf{N}$ & $\%$ \\
\hline \multicolumn{9}{|l|}{ Idade } \\
\hline Até 25 anos & 4 & 0,8 & 3 & 1,9 & 0 & 0,0 & 7 & 0,8 \\
\hline De 26 a 30 anos & 15 & 2,8 & 29 & 18,5 & 11 & 5,1 & 55 & 6,1 \\
\hline De 31 a 35 anos & 48 & 9,0 & 22 & 14,0 & 18 & 8,4 & 88 & 9,7 \\
\hline De 36 a 40 anos & 141 & 26,5 & 39 & 24,8 & 25 & 11,7 & 205 & 22,7 \\
\hline De 41 a 45 anos & 145 & 27,3 & 30 & 19,1 & 40 & 18,7 & 215 & 23,8 \\
\hline De 46 a 50 anos & 71 & 13,3 & 23 & 14,6 & 59 & 27,6 & 153 & 16,9 \\
\hline 51 anos ou mais & 108 & 20,3 & 11 & 7,0 & 61 & 28,5 & 180 & 19,9 \\
\hline \multicolumn{9}{|l|}{ Sexo } \\
\hline Feminino & 80 & 15,1 & 22 & 14,0 & 22 & 9,9 & 124 & 13,6 \\
\hline Masculino & 451 & 84,9 & 135 & 86,0 & 200 & 90,1 & 786 & 86,4 \\
\hline \multicolumn{9}{|l|}{ Cor da pele } \\
\hline Branca & 338 & 63,7 & 100 & 63,7 & 127 & 59,3 & 565 & 62,6 \\
\hline Preta & 20 & 3,8 & 7 & 4,5 & 10 & 4,7 & 37 & 4,1 \\
\hline Parda & 169 & 31,8 & 50 & 31,8 & 76 & 35,5 & 295 & 32,7 \\
\hline Amarela/Indígena & 4 & 0,8 & 0 & 0,0 & 1 & 0,5 & 5 & 0,6 \\
\hline \multicolumn{9}{|l|}{ Estado civil } \\
\hline Solteiro(a) & 68 & 12,8 & 33 & 21,0 & 20 & 9,3 & 121 & 13,4 \\
\hline Casado(a) & 402 & 75,7 & 108 & 68,8 & 169 & 78,2 & 679 & 75,1 \\
\hline Viúvo(a) & 8 & 1,5 & 3 & 1,9 & 6 & 2,8 & 17 & 1,9 \\
\hline Separado(a) & 53 & 10,0 & 13 & 8,3 & 21 & 9,7 & 87 & 9,6 \\
\hline \multicolumn{9}{|l|}{ Escolaridade } \\
\hline $1^{\circ} \mathrm{Grau}$ incompleto & 1 & 0,2 & 0 & 0,0 & 1 & 0,5 & 2 & 0,2 \\
\hline $1^{\circ} \mathrm{Grau}$ completo & 6 & 1,1 & 0 & 0,0 & 1 & 0,5 & 7 & 0,8 \\
\hline $2^{\circ} \mathrm{Grau}$ incompleto & 16 & 3,0 & 1 & 0,6 & 2 & 0,9 & 19 & 2,1 \\
\hline $2^{\circ} \mathrm{Grau}$ completo & 55 & 10,4 & 19 & 12,1 & 30 & 13,5 & 104 & 11,5 \\
\hline Superior incompleto & 127 & 24,1 & 59 & 37,6 & 40 & 18,0 & 226 & 24,9 \\
\hline Superior completo & 298 & 56,4 & 68 & 43,3 & 118 & 53,2 & 484 & 53,4 \\
\hline Pós-graduação & 23 & 4,4 & 10 & 6,4 & 29 & 13,1 & 62 & 6,8 \\
\hline Outra & 2 & 0,4 & 0 & 0,0 & 1 & 0,5 & 3 & 0,3 \\
\hline \multicolumn{9}{|l|}{ Renda } \\
\hline Até $\mathrm{R} \$ 500$ & 4 & 0,8 & 0 & 0,0 & 1 & 0,5 & 5 & 0,6 \\
\hline $\mathrm{R} \$ 501$ a $\mathrm{R} \$ 1.000$ & 68 & 13,0 & 0 & 0,0 & 6 & 2,7 & 74 & 8,2 \\
\hline $\mathrm{R} \$ 1.001$ a $\mathrm{R} \$ \mathrm{R} \$ 1.500$ & 305 & 58,1 & 22 & 14,0 & 23 & 10,4 & 350 & 38,8 \\
\hline $\mathrm{R} \$ 1.501$ a $\mathrm{R} \$ 2.500$ & 110 & 21,0 & 116 & 73,9 & 114 & 51,6 & 340 & 37,7 \\
\hline $\mathrm{R} \$ 2.501$ a $\mathrm{R} \$ 4.000$ & 16 & 3,0 & 17 & 10,8 & 55 & 24,9 & 88 & 9,7 \\
\hline Mais de $\mathrm{R} \$ 4.000$ & 22 & 4,2 & 2 & 1,3 & 22 & 10,0 & 46 & 5,1 \\
\hline
\end{tabular}

especialmente os percentuais encontrados para as dimensões: apoio de informação e apoio material (Tabela 3).

Os resultados da modelagem podem ser vistos na Tabela 4. No modelo hierárquico usado foram incluídas no primeiro bloco as variáveis: idade, sexo e situação conjugal, das quais todas se mostraram significativas. Com a inserção das variáveis do segundo bloco, relativo à qualidade de vida, verificou-se que a variável idade (do primeiro bloco) deixou de ser significativa. Dentre as variáveis do segundo bloco se mostraram sig- nificativas o grau de satisfação com a vida como um todo e o grau de satisfação com a capacidade de reagir a situações difíceis. A entrada das variáveis do terceiro bloco, referente às condições de saúde, mostrou que sexo e situação conjugal (bloco 1) deixaram de ser significativas, enquanto as variáveis do segundo bloco permaneceram significativas. Entre as novas variáveis incluídas se mostraram relacionadas ao sofrimento psíquico a prática de atividades físicas e os problemas de saúde relacionados ao sistema nervoso. Por fim, com a inclusão do último bloco de variáveis, que 
Tabela 2. Condições de trabalho de policiais civis do Estado do Rio de Janeiro, segundo localização da unidade (Capital, Interior e Baixada).

\begin{tabular}{|c|c|c|c|c|c|c|c|c|}
\hline \multirow{2}{*}{ Condições de trabalho } & \multicolumn{2}{|c|}{ Capital } & \multicolumn{2}{|c|}{ Interior } & \multicolumn{2}{|c|}{ Baixada } & \multicolumn{2}{|c|}{ Total } \\
\hline & $\mathbf{N}$ & $\%$ & $\mathbf{N}$ & $\%$ & $\mathbf{N}$ & $\%$ & $\mathbf{N}$ & $\%$ \\
\hline \multicolumn{9}{|l|}{ Tempo na polícia } \\
\hline Até 5 anos & 51 & 9,6 & 54 & 34,8 & 5 & 2,3 & 110 & 12,2 \\
\hline De 6 a 10 anos & 28 & 5,3 & 32 & 20,6 & 62 & 28,8 & 122 & 13,5 \\
\hline De 11 a 15 anos & 230 & 43,3 & 15 & 9,7 & 7 & 3,3 & 252 & 28,0 \\
\hline De 16 a 20 anos & 92 & 17,3 & 38 & 24,5 & 41 & 19,1 & 171 & 19,0 \\
\hline De 21 a 25 anos & 42 & 7,9 & 10 & 6,5 & 63 & 29,3 & 115 & 12,8 \\
\hline 26 anos ou mais & 88 & 16,6 & 6 & 3,9 & 37 & 17,2 & 131 & 14,5 \\
\hline \multicolumn{9}{|l|}{ Vida após entrar na polícia } \\
\hline Melhorou & 327 & 62,3 & 110 & 69,6 & 124 & 57,9 & 561 & 62,5 \\
\hline Continua igual & 127 & 24,2 & 36 & 22,8 & 58 & 27,1 & 221 & 24,6 \\
\hline Piorou & 71 & 13,5 & 12 & 7,6 & 32 & 15,0 & 115 & 12,8 \\
\hline \multicolumn{9}{|l|}{ Exercer trabalho para o qual treinou } \\
\hline Sim & 404 & 78,1 & 117 & 74,1 & 143 & 69,4 & 664 & 75,4 \\
\hline Não & 113 & 21,9 & 41 & 25,9 & 63 & 30,6 & 217 & 24,6 \\
\hline \multicolumn{9}{|l|}{ Trabalhar além do horário } \\
\hline Sim, muitas vezes & 305 & 63,5 & 83 & 52,9 & 131 & 60,4 & 519 & 60,8 \\
\hline Sim, algumas vezes & 113 & 23,5 & 49 & 31,2 & 50 & 23,0 & 212 & 24,8 \\
\hline Sim, poucas vezes & 25 & 5,2 & 14 & 8,9 & 17 & 7,8 & 56 & 6,6 \\
\hline Não & 37 & 7,7 & 11 & 7,0 & 19 & 8,8 & 67 & 7,8 \\
\hline \multicolumn{9}{|c|}{ Exercer outra atividade fora da polícia } \\
\hline $\operatorname{Sim}$ & 288 & 55,8 & 31 & 19,7 & 97 & 45,1 & 416 & 46,8 \\
\hline Não & 228 & 44,2 & 126 & 80,3 & 118 & 54,9 & 472 & 53,2 \\
\hline \multicolumn{9}{|l|}{ Exercer atividade policial onde mora } \\
\hline Sim & 87 & 16,8 & 80 & 51,3 & 40 & 18,6 & 207 & 23,3 \\
\hline Não & 431 & 83,2 & 76 & 48,7 & 175 & 81,4 & 682 & 76,7 \\
\hline \multicolumn{9}{|l|}{ Estresse no trabalho } \\
\hline Passivo & 67 & 13,4 & 9 & 5,8 & 27 & 13,6 & 103 & 12,1 \\
\hline Baixo desgaste & 125 & 25,0 & 7 & 4,5 & 24 & 12,1 & 156 & 18,3 \\
\hline Alto desgaste & 85 & 17,0 & 21 & 13,6 & 62 & 31,3 & 168 & 19,7 \\
\hline Ativo & 224 & 44,7 & 117 & 76,0 & 85 & 42,9 & 426 & 49,9 \\
\hline \multicolumn{9}{|l|}{ Risco percebido } \\
\hline Ausência & 24 & 4,7 & 19 & 12,1 & 4 & 2,0 & 47 & 5,4 \\
\hline Presença & 486 & 95,3 & 138 & 87,9 & 199 & 98,0 & 823 & 94,6 \\
\hline \multicolumn{9}{|l|}{ Vitimização } \\
\hline Ausência & 395 & 79,0 & 140 & 90,3 & 177 & 86,3 & 712 & 82,8 \\
\hline Presença & 105 & 21,0 & 15 & 9,7 & 28 & 13,7 & 148 & 17,2 \\
\hline
\end{tabular}

se referia às condições de trabalho, levou à perda de significância da variável prática de atividade física. Dentre as variáveis desse último bloco se mostraram associadas ao sofrimento psíquico: exercer trabalho para o qual foi treinado, vitimização e localização da unidade (Capital, Interior ou Baixada).

Portanto, constituem o modelo final as seguintes variáveis: grau de satisfação com a vida como um todo, grau de satisfação com a capacidade de reagir a situações difíceis, problemas de saúde relacionados ao sistema nervoso, exercer trabalho para o qual foi treinado, vitimização e localização da unidade (Capital, Interior ou Baixada).
Observa-se na Tabela 5 que a chance de sofrimento psíquico entre os policiais que se sentiam "nem satisfeitos nem insatisfeitos" e aqueles que se disseram "insatisfeitos ou muito insatisfeitos" com sua capacidade de reagir a situações difíceis foram, respectivamente, 1,51 e 10,85 a daqueles que se mostraram "satisfeitos ou muito satisfeitos”. Em relação ao grau de satisfação com a vida como um todo, observou-se uma chance 6,69 vezes entre os que se declararam "insatisfeitos ou muito insatisfeitos" em relação aos que informaram estar "satisfeitos ou muito satisfeitos". A presença de problemas do sistema nervoso significou uma razão de chances (OR) de 7,25, ou 
Tabela 3. Condições de saúde e qualidade de vida de policiais civis do Estado do Rio de Janeiro, segundo localização da unidade (Capital, Interior e Baixada).

\begin{tabular}{|c|c|c|c|c|c|c|c|c|}
\hline \multirow{2}{*}{ Variável } & \multicolumn{2}{|c|}{ Capital } & \multicolumn{2}{|c|}{ Interior } & \multicolumn{2}{|c|}{ Baixada } & \multicolumn{2}{|c|}{ Total } \\
\hline & $\mathbf{N}$ & $\%$ & $\mathbf{N}$ & $\%$ & $\mathbf{N}$ & $\%$ & $\mathbf{N}$ & $\%$ \\
\hline \multicolumn{9}{|l|}{ Condições de saúde } \\
\hline \multicolumn{9}{|l|}{ Presença de problemas de saúde } \\
\hline Colesterol alto & 167 & 32,8 & 35 & 22,6 & 83 & 40,1 & 285 & 32,7 \\
\hline Lesões permanentes causadas pelo trabalho & 29 & 6,1 & 4 & 2,8 & 20 & 9,8 & 53 & 6,4 \\
\hline Problemas no aparelho respiratório & 181 & 35,6 & 67 & 42,9 & 86 & 41,5 & 334 & 38,3 \\
\hline Problema no sistema digestivo & 199 & 39,1 & 46 & 29,5 & 79 & 38,0 & 324 & 37,1 \\
\hline Problema nos músculos, ossos e pele & 337 & 66,5 & 84 & 53,8 & 149 & 72,3 & 570 & 65,6 \\
\hline Problemas glandulares & 51 & 10,0 & 12 & 7,7 & 32 & 15,5 & 95 & 10,9 \\
\hline Doenças transmissíveis & 118 & 23,3 & 7 & 4,5 & 19 & 9,2 & 144 & 16,6 \\
\hline Problemas de visão, audição e fala & 310 & 60,8 & 81 & 51,9 & 146 & 69,9 & 537 & 61,4 \\
\hline Problemas no coração e aparelho circulatório & 23 & 23,2 & 25 & 16,2 & 73 & 35,3 & 121 & 26,3 \\
\hline Problemas do sistema nervoso & 179 & 35,2 & 78 & 50,0 & 73 & 35,6 & 330 & 37,9 \\
\hline Problemas no aparelho urinário & 85 & 16,8 & 21 & 13,5 & 37 & 18,0 & 143 & 16,5 \\
\hline Consumo de substâncias & 83 & 16,7 & 34 & 22,2 & 32 & 15,7 & 149 & 17,5 \\
\hline \multicolumn{9}{|l|}{ Prática de esportes } \\
\hline 4 ou mais vezes por semana & 34 & 6,7 & 20 & 12,9 & 20 & 9,6 & 74 & 8,5 \\
\hline De 2 a 3 vezes por semana & 34 & 6,7 & 40 & 25,8 & 48 & 23,1 & 122 & 14,0 \\
\hline Uma vez por semana & 98 & 19,3 & 11 & 7,1 & 35 & 16,8 & 144 & 16,5 \\
\hline De 2 a 3 vezes por mês & 64 & 12,6 & 18 & 11,6 & 12 & 5,8 & 94 & 10,8 \\
\hline Poucas vezes por ano & 28 & 5,5 & 13 & 8,4 & 27 & 13,0 & 68 & 7,5 \\
\hline Não pratico & 251 & 49,3 & 53 & 34,2 & 66 & 31,7 & 370 & 42,4 \\
\hline \multicolumn{9}{|l|}{ Qualidade de Vida } \\
\hline \multicolumn{9}{|l|}{ Grau de satisfação - reação a situações difíceis } \\
\hline Muito satisfeito/satisfeito & 459 & 87,4 & 138 & 87,9 & 167 & 78,4 & 764 & 85,4 \\
\hline Nem satisfeito/nem insatisfeito & 46 & 8,8 & 12 & 7,6 & 34 & 16 & 92 & 10,3 \\
\hline Insatisfeito/muito insatisfeito & 20 & 3,8 & 7 & 4,5 & 12 & 5,6 & 39 & 4,4 \\
\hline \multicolumn{9}{|l|}{ Grau de satisfação - vida como um todo } \\
\hline Muito satisfeito/satisfeito & 415 & 78,6 & 135 & 86 & 150 & 69,4 & 700 & 77,7 \\
\hline Nem satisfeito/nem insatisfeito & 80 & 15,2 & 14 & 8,9 & 48 & 22,2 & 142 & 15,8 \\
\hline Insatisfeito/muito insatisfeito & 33 & 6,3 & 8 & 5,1 & 18 & 8,3 & 59 & 6,5 \\
\hline \multicolumn{9}{|l|}{ Apoio Social } \\
\hline Emocional - alto & 266 & 51,2 & 89 & 56,3 & 99 & 47,4 & 454 & 51,2 \\
\hline Emocional - baixo & 254 & 48,8 & 69 & 43,7 & 110 & 52,6 & 433 & 48,8 \\
\hline Informação - alto & 315 & 60,9 & 115 & 73,2 & 105 & 50,2 & 535 & 60,6 \\
\hline Informação - baixo & 202 & 39,1 & 42 & 26,8 & 104 & 49,8 & 348 & 39,4 \\
\hline Interação positiva - alto & 279 & 54,3 & 91 & 57,6 & 102 & 49,5 & 472 & 53,8 \\
\hline Interação positiva - baixo & 235 & 45,7 & 67 & 42,4 & 104 & 50,5 & 406 & 46,2 \\
\hline Material - alto & 316 & 61,4 & 90 & 57 & 100 & 48,1 & 506 & 57,4 \\
\hline Material - baixo & 199 & 38,6 & 68 & 43 & 108 & 51,9 & 375 & 42,6 \\
\hline Afetivo - alto & 282 & 54,2 & 87 & 55,1 & 108 & 50,9 & 477 & 53,6 \\
\hline Afetivo - baixo & 238 & 45,8 & 71 & 44,9 & 104 & 49,1 & 413 & 46,4 \\
\hline Presença de Sofrimento psíquico & 97 & 20,0 & 22 & 14,5 & 56 & 28,6 & 175 & 21,0 \\
\hline
\end{tabular}

seja, uma chance seis vezes maior em relação àqueles que não mencionaram tais problemas. Não exercer o trabalho para o qual foi treinado também resultou em aumento da chance de sofrimento psíquico $(\mathrm{OR}=1,68$; IC95\% $=1,08-$ $2,62)$. Aqueles que informaram ter sido vitimizados tiveram uma chance 3,08 vezes a daqueles que não relataram tal experiência. Por fim, atuar no Interior representou um fator de proteção $(\mathrm{OR}=0,48)$ em relação a trabalhar na Capital. Os policiais da Baixada, por sua vez, apresentaram risco ligeiramente maior em relação aos da Capital (OR = 1,66; IC95\% = 1,02-2,69). 
Tabela 4. Variáveis associadas ao sofrimento psíquico de policiais civis do Estado do Rio de Janeiro, segundo modelo hierarquizado.

\begin{tabular}{|c|c|c|c|c|c|}
\hline \multirow[t]{2}{*}{ Bloco } & \multirow[t]{2}{*}{ Variáveis } & Modelo 1 & Modelo 2 & Modelo 3 & Modelo 4 \\
\hline & & \multicolumn{4}{|c|}{ Teste de Wald (P-valor) } \\
\hline \multirow[t]{3}{*}{ PERFIL } & Idade & 0,026 & 0,282 & - & - \\
\hline & Sexo & 0,016 & 0,018 & 0,186 & - \\
\hline & Situação conjugal & 0,000 & 0,033 & 0,908 & - \\
\hline QUALIDADE & Propriedade da residência & - & 0,626 & - & - \\
\hline \multirow[t]{7}{*}{ DE VIDA } & $\begin{array}{l}\text { Grau de satisfação com sua capacidade de reagir a } \\
\text { situações difíceis }\end{array}$ & - & 0,006 & 0,016 & 0,002 \\
\hline & Grau de satisfação com sua vida como um todo & - & 0,000 & 0,000 & 0,000 \\
\hline & Apoio emocional & - & 0,393 & - & - \\
\hline & Apoio de informação & - & 0,825 & - & - \\
\hline & Interação positiva & - & 0,638 & - & - \\
\hline & Apoio material & - & 0,808 & - & - \\
\hline & Apoio afetivo & - & 0,538 & - & - \\
\hline CONDIÇÕES & Prática de atividades físicas & - & - & 0,012 & 0,077 \\
\hline \multirow[t]{12}{*}{ DE SAÚDE } & Colesterol alto & - & - & 0,839 & - \\
\hline & Lesões permanentes causadas pelo trabalho & - & - & 0,374 & - \\
\hline & Problemas no aparelho respiratório & - & - & 0,281 & - \\
\hline & Problemas no coração e aparelho circulatório & - & - & 0,152 & - \\
\hline & Problemas no sistema digestivo & - & - & 0,116 & - \\
\hline & Problemas nos músculos, ossos e pele & - & - & 0,065 & - \\
\hline & Problemas glandulares & - & - & 0,864 & - \\
\hline & Problemas do sistema nervoso & - & - & 0,006 & 0,000 \\
\hline & Problemas no aparelho urinário & - & - & 0,213 & - \\
\hline & Doenças transmissíveis & - & - & 0,163 & - \\
\hline & Problemas de visão, audição e fala & - & - & 0,273 & - \\
\hline & Consumo de substâncias & - & - & 0,094 & - \\
\hline CONDIÇÕES & Tempo de serviço & - & - & - & 0,133 \\
\hline \multirow[t]{9}{*}{ DE TRABALHO } & Vida após entrar na polícia & - & - & - & 0,589 \\
\hline & Exercer trabalho para o qual foi treinado & - & - & - & 0,050 \\
\hline & Trabalhar além do horário & - & - & - & 0,605 \\
\hline & Exercer outra atividade fora da polícia & - & - & - & 0,460 \\
\hline & Exercer atividade policial onde mora & - & - & - & 0,084 \\
\hline & Estresse no trabalho & - & - & - & 0,191 \\
\hline & Percepção de risco & - & - & - & 0,605 \\
\hline & Vitimização & - & - & - & 0,003 \\
\hline & Local onde trabalha (Capital, Interior ou Baixada) & - & - & - & 0,002 \\
\hline
\end{tabular}

\section{Discussão}

Este artigo possibilitou a obtenção de uma série de informações relevantes sobre os policiais civis do Estado do Rio de Janeiro. Entre os achados observou-se mais sofrimento psíquico, segundo a SRQ20 , em policiais civis da Baixada (28,6\%), seguidos pelos da Capital (20,0\%) e os do Interior (14,5\%).

A análise efetuada por meio de um modelo de regressão logística hierarquizado para identificar fatores associados ao sofrimento psíquico encontrou associação com várias condições ligadas ao trabalho, como o grau de satisfação com a capacidade de reagir a situações difíceis, exercer trabalho para o qual foi treinado, vitimização e localização da unidade (Capital, Interior ou Baixada), mas também encontrou associação com problemas de saúde como os relacionados ao sistema nervoso. Finalmente, verificou-se relação do sofrimento psíquico com um indicador de qualidade de vida, que é o grau de satisfação com a vida como um todo. 
Tabela 5. Fatores associados ao sofrimento psíquico de policiais civis do Estado do Rio de Janeiro (modelo final).

\begin{tabular}{|c|c|c|c|c|c|c|}
\hline Bloco & Variáveis/categorias & $\begin{array}{c}\text { Prevalência } \\
\%\end{array}$ & $\begin{array}{c}\text { OR } \\
\text { bruta }\end{array}$ & IC $95 \%$ & $\begin{array}{c}\text { OR } \\
\text { ajustada }\end{array}$ & IC 95\% \\
\hline \multirow[t]{8}{*}{$\begin{array}{l}\text { QUALIDADE } \\
\text { DE VIDA }\end{array}$} & $\begin{array}{l}\text { Grau de satisfação com a capacidade de reagir } \\
\text { a situações difíceis }\end{array}$ & & & & & \\
\hline & Muito satisfeito/satisfeito & 83,6 & & & & \\
\hline & Nem satisfeito/nem insatisfeito & 10,1 & 2,27 & $1,34-3,74$ & 1,51 & $0,82-2,77$ \\
\hline & Insatisfeito/muito insatisfeito & 4,3 & 10,83 & $5,03-23,33$ & 10,85 & $4,07-28,92$ \\
\hline & Grau de satisfação com a vida como um todo & & & & & \\
\hline & Muito satisfeito/satisfeito & 76,6 & & & & \\
\hline & Nem satisfeito/nem insatisfeito & 15,5 & 3,77 & $2,48-5,72$ & 3,50 & $2,10-5,83$ \\
\hline & Insatisfeito/muito insatisfeito & 6,5 & 7,74 & $4,22-14,18$ & 6,69 & $3,07-14,58$ \\
\hline CONDIÇÕES & Problema no sistema nervoso & & & & & \\
\hline \multirow{2}{*}{ DE SAÚDE } & Sim & 59,1 & 5,54 & $3,84-7,98$ & 7,25 & $4,67-11,26$ \\
\hline & Não & 36,1 & & & & \\
\hline CONDIÇÕES & Exercer o trabalho para o qual foi treinado & & & & & \\
\hline \multirow[t]{9}{*}{ DE TRABALHO } & Sim & 72,6 & & & & \\
\hline & Não & 23,7 & 2,21 & $1,53-3,18$ & 1,68 & $1,08-2,62$ \\
\hline & Vitimização & & & & & \\
\hline & Ausência & 77,9 & & & & \\
\hline & Presença & 16,2 & 3,39 & $2,29-5,00$ & 3,08 & $1,91-4,96$ \\
\hline & Local & & & & & \\
\hline & Capital & 58,3 & & & & \\
\hline & Interior & 17,4 & 0,68 & $0,41-1,12$ & 0,48 & $0,26-0,88$ \\
\hline & Baixada & 24,3 & 1,60 & $1,09-2,34$ & 1,66 & $1,02-2,69$ \\
\hline
\end{tabular}

Alguns desses resultados são corroborados por Souza et al. ${ }^{28}$ que pesquisaram policiais militares da cidade do Rio de Janeiro e encontraram que trabalhar além do horário, sem que seja por vontade própria, apresentar estresse e sofrer alguma vitimização são fatores que estão correlacionados com sofrimento psíquico. Vários estudos já apontaram para os efeitos das condições de trabalho na saúde física e mental dos policiais, e na sua qualidade de vida ${ }^{29-32}$.

Os estudos de Sennet ${ }^{33}$ mostram também que ao compartilhar o mundo do trabalho o sujeito busca conquistar uma identidade que obtenha o reconhecimento social, intimamente ligado à ideia de competência e de pertencimento. Portanto, é importante refletir sobre os elementos que compõem as atividades laborais e que a realização dessas atividades satisfaz as necessidades do trabalhador, pois a relação do sujeito com seu trabalho se constitui como a própria finalidade da vida. Por isto, quanto mais o sujeito estiver instrumentalizado e familiarizado com seu trabalho, mais será capaz de obter recompensa emocional, ou seja, sentir-se competente. Ao escolher uma profissão o sujeito, naturalmente o faz por afinidade (familiaridade) com o que, como, onde e quando irá exercer suas atividades. No caso dos policiais do Rio de Janeiro essa familiaridade parece ser rompida e ocorrer um estranhamento na medida em que ele é intimado a trabalhar além do seu horário habitual e não no tempo convencionado para o exercício das atividades de seu processo de trabalho.

Muitas vezes, para suportar ou burlar o sofrimento causado pela incompatibilidade entre o horário de trabalho previsto e o que na realidade ele cumpre, o policial escapa às regras estabelecidas criando um fosso entre o trabalho real - aquilo que ele executa - e o trabalho prescrito, o que o coloca numa posição de sigilo e segredo sobre sua maneira própria de desenvolver suas atividades, como uma forma de proteção, mas que ao mesmo tempo se revela no isolamento, inibição, sentimento de medo, agressividade, ansiedade.

É desse modo, que os policiais desenvolvem mecanismos relativamente eficientes para lidar com essa realidade, construindo para si uma imagem do trabalho policial que lhes garanta algum tipo de satisfação pessoal. A isso denominamos 
como modos de reapropriação eficaz, onde o exercício profissional, aparentemente satisfatório, funciona como nexo, e não como falta de nexo.

Do ponto de vista das localidades pesquisadas é importante ressaltar a existência de heterogeneidades inter e intra-áreas que, provavelmente, ajudam a explicar as diferenças encontradas. Capital, Baixada Fluminense e Interior do Estado do Rio de Janeiro conformam áreas com diferenciações tanto socioeconômicas, geopolíticas e culturais, como nos processos de criminalidade e delitos nelas cometidos. Enquanto a Capital do Estado é uma das mais importantes cidades do país e onde há mais registros de crimes contra o patrimônio, a Baixada Fluminense é uma área periférica pertencente à Região Metropolitana do Rio de Janeiro, palco histórico dos mais frequentes registros de crimes contra a pessoa ${ }^{18}$. Alguns de seus municípios apresentam taxas de homicídios bem acima da média nacional ${ }^{34}$. Já o Interior do Estado está constituído por municípios menos povoados, vários deles com pouca expressão socioeconômica e índices de violência menores, se comparados aos das outras duas áreas ${ }^{17}$.

Nesses distintos cenários, a relação com o trabalho e as reações aos impactos que o trabalho produz em cada indivíduo se apresentam de maneira singular, particularizada ${ }^{35}$, mas também como uma ordem simbólica estruturante de uma realidade coletiva ${ }^{36,37}$. No caso dos policiais, pelos riscos a que estão expostos no desempenho de suas atividades cotidianas, principalmente ao lidar com a morte ou a sua eminência, essa relação com o trabalho pode ser, como observado, de intenso sofrimento psíquico.

Alguns dados ajudam a entender o fato da Baixada ter apresentado a maior proporção de sofrimento psíquico. Entre os policiais dessa área observou-se mais sentimento de que a vida piorou ao ingressar na Polícia, mais alto desgaste (grande demanda e pouco controle), mais problemas de saúde, talvez pelo fato de serem mais velhos que os demais, menos satisfação com a vida e menos apoio social. Uma hipótese a ser investigada, para além das dinâmicas criminais e características da área, é a da existência de um efeito de gênero nestes resultados, devido à maior participação feminina entre os policiais respondentes desta área. As mulheres sobrepõem exigências domésticas e do trabalho e, assim, vivem tensões e conflitos que podem resultar em sofrimento psíquico ${ }^{38}$.

Por outro lado trabalhar no Interior do Estado parece ter um efeito protetor para o sofrimento psíquico. Pode contribuir para isso o fato dos respondentes terem trabalho mais ativo (ele- vada demanda e controle sobre ela), serem mais jovens e estar a menos tempo na polícia que seus colegas das outras áreas estudadas, morarem perto do local de trabalho e se sentirem mais satisfeitos com a vida. Entretanto, condições adversas também foram observadas entre eles, como a maior frequência de problemas do sistema nervoso e de consumo de substâncias. Outrossim, um fator explicativo para o menor sofrimento psíquico observado nesta área pode ser a sua sub-representação, pois a pesquisa abrangeu apenas 7,7\% das Delegacias de Polícia do Interior, enquanto na Baixada e na Capital foram incluídas praticamente todas as Delegacias.

$\mathrm{Na}$ Capital, os policiais são mais vitimizados $(21,0 \%)$ e trabalham mais além do horário que seus colegas do Interior e da Baixada.

$\mathrm{O}$ fato de nos três segmentos analisados mais de $80 \%$ dos policiais afirmarem que trabalham muitas ou algumas vezes além do horário pode colaborar para os níveis observados de estresse ocupacional. Para 31,3\% dos policiais da Baixada o trabalho na Polícia gera alto desgaste (muita demanda e pouco controle). Este percentual foi de 17,0\% nos policiais da Capital e de 13,2\% nos policiais do Interior. Luz $^{39}$ e Bezerra ${ }^{40}$ estudaram estresse ocupacional em mulheres policiais militares da cidade do Rio de Janeiro e aprofundaram essas questões, identificando que ocorre alto desgaste quando o trabalho além do horário é imposto e não por vontade própria.

A organização do trabalho parece ter um papel fundamental no sofrimento psíquico. Na presente análise observou-se que $21 \%$ do conjunto dos policiais que atuam nas delegacias de polícia das três áreas estudadas padecem de sofrimento mental. São eles os que estão à frente do atendimento ao público e das investigações de todas as queixas e delitos que nelas são registrados. Estudo de Souza et al. ${ }^{41}$ com o conjunto dos policiais civis da Capital mostrou menores percentuais entre os policiais lotados no setor administrativo $(19,5 \%)$ e dos que trabalham no setor técnico $(15,1 \%)$. Outro estudo de Souza et al. ${ }^{28}$ reforça a hipótese de que atuar na linha de frente da segurança pública lidando com o público é um fator gerador de sofrimento psíquico, pois encontrou 35,7\% de policiais militares nessa condição.

Para minimizar ou dirimir situações dessa natureza, Dejours ${ }^{42}$ assinala a pertinência de espaços públicos (espaços de fala) onde os trabalhadores possam participar do planejamento das atividades que irão desenvolver na Instituição, como uma forma de preencher o fosso entre o trabalho real e o que é prescrito e dar um significado criativo às tarefas que lhes são atribuídas. 
Finalmente, é importante apontar alguns limites do presente estudo. Primeiro, pelo fato de ser um estudo transversal, não permite inferências temporais entre a exposição à variável e o desfecho investigado. Segundo, pelos distintos desenhos amostrais, pelas diferentes formas de coleta de dados e pela seleção não aleatória dos sujeitos, é possível que vieses de seleção tenham sido introduzidos e estejam afetando os resultados.

\section{Considerações finais}

A título de conclusão é necessário enfatizar o amplo campo de conhecimentos que os estudos com os agentes da segurança pública ajudam a demarcar, não deixando de enfatizar que muitas hipóteses, algumas delas aqui explicitadas, ainda estão por ser testadas e que muita pesquisa ainda necessita ser desenvolvida.

Estudos como este permitem que se tenha um lampejo sobre como as condições de trabalho acometem a saúde e a qualidade de vida do policial, sendo uma contribuição para políticas públicas de atenção e de prevenção para os problemas identificados, mas também visa a enfatizar a importância de se valorizar esse trabalhador a fim de lhe garantir condições dignas de trabalho e de vida, pois o fazer desses profissionais se apresenta como o lugar do imprevisto e do não programado.

A exigência de ter que responder com eficiência às solicitações que lhe são dirigidas pode gerar uma série de problemas de saúde e interferir na competência do policial para enfrentar os desafios, os riscos, os conflitos e os improvisos que uma atividade dessa natureza exige.

Várias das questões ressaltadas neste estudo são estruturais e demandam a necessidade de um planejamento eficiente e eficaz na organização do processo de trabalho dos policiais. Nesse sentido, o Estado é chamado a responder às expectativas desses agentes da segurança pública e empreender ações que garantam a segurança e os direitos do policial no exercício de suas funções, tendo em vista que são esses agentes que têm como missão proteger e fornecer segurança à população.

\section{Colaboradores}

LW Pinto, AEB Figueiredo e ER Souza participaram igualmente de todas as etapas de elaboração do artigo.

\section{Referências}

1. Bertão FRBM, Hashimoto F. Entre o desejo e o sofrimento psíquico no trabalho. Psicologia em Revista 2006; 12(20):141-163.

2. Freud S. A Psicopatologia de Grupo e a Análise do Ego. Rio de Janeiro: Imago; 1969.

3. Jardim SR. O Trabalho e a Construção do Sujeito. In: Silva Filho JF, Jardim SR, organizadores. A Danação do Trabalho: relações de trabalho e o sofrimento. Rio de Janeiro: Te Corá; 1997.

4. Silva Filho JF. O trabalho da Interpretação. In: Silva Filho JF, Jardim SR, organizadores. A Danação do Trabalho: relações de trabalho e o sofrimento. Rio de Janeiro: Te Corá; 1997.

5. Mendes AM. Valores e prazer-sofrimento no contexto organizacional [tese]. Brasília: Universidade de Brasília; 1999.

6. Greco RM, Oliveira VM, Gomes JR. Cargas de trabalho dos técnicos operacionais da escola de enfermagem da Universidade de São Paulo. Revista Brasileira de Saúde Ocupacional 1996; 25:59-75.

7. Laurell A, Noriegam M. Processo de produção e saúde: trabalho e desgaste operário. São Paulo: Hucitec; 1989.

8. Sauter, SL, Brightwell WS, Colligan MJ, Hurrell Jr JJ, Katz TM, LeGrande DE, Lessin N, Lippin RA, Lipscomb JA, Murphy LR, Peters RH, Keita GP, Robertson SR, Stellman, JM, Swanson NG, Tetrick LE. The changing organization of work and the safety and health of working people. Department of Health and Human Services; 2002. 
9. Dejours C. A loucura do trabalho: estudo de psicopatologia do trabalho. 5a Edição. São Paulo: Cortez-Oboré; 1992.

10. Derriennic F. Approche épistémologique de la souffrance au travail: l'objetivacion du vécu est-elle possible? Revue Internationale de Psychosologie 1996; 3(5):107-125.

11. Perilleux T. Entre Le spectacle de la souffrance et l'engagemnt dans l'action. Revue Internationale de Psychosologie 1996; 3(5):127-139.

12. Mendes AM. Inventário de prazer-sofrimento no trabalho: validação do instrumento. In: XXVI Congresso Interamericano de Psicologia; 1997; São Paulo. p. 93.

13. Dejours C. A Banalização da Injustiça Social. Rio de Janeiro: Editora FGV; 1999

14. Morrone CF. "Só para não ficar desempregado". Ressignificando o sofrimento psíquico no trabalho: estudo com trabalhadores em atividades informais [dissertação]. Brasília (DF): Universidade de Brasília; 2001.

15. Minayo MCS, Souza ER. Missão investigar: entre o ideal e a realidade de ser policial. Rio de Janeiro: Garamond; 2003.

16. Lima RK. Polícia e exclusão na cultura judiciária. Tempo Social: Revista de Sociologia da USP 1997; 9(1):169-183.

17. Souza ER, Constantino P, Ribeiro A, Carmo C. Condições de trabalho e saúde de policiais civis do interior do estado do Rio de Janeiro [Relatório de pesquisa]: Claves; 2008.

18. Souza ER, Constantino P. Condições de saúde, trabatho e qualidade de vida de policiais civis da Baixada Fluminense [Relatório de pesquisa]: CLAVES; 2011.

19. Minayo MCS, Assis SG, Souza ER, organizadoras. Avaliação por triangulação de métodos: abordagem de programas sociais. Rio de Janeiro: Editora Fiocruz; 2005.

20. Harding TW, Arango MV, Baltazar J, Climent CE, Ibrahim HH, Ladrido-Ignacio L, Murthy RS, Wig NN. Mental disorders in primary health care: a study of their frequency and diagnosis in four developing countries. Psychol Med 1980; 10(2):231-241.

21. Mari JJ, Willians PA. Comparison of the validity of two psychiatric screening questionnaires (GHQ-12 and SRQ-20) in Brazil, using Relative Operating Characteristic (ROC) analysis. Psychol Med 1985; 15(3):651-659.

22. Sherbourne CD, Stewart AL. The MOS Social Support Survey. Social Science and Medicine 1991; 38:705714.

23. Chor D, Griep RH, Lopes CS, Faerstein E. Medidas de rede e apoio social no Estudo Pró-Saúde: prétestes e estudo piloto. Cad Saude Publica 2001; 17(4):887-896.

24. Karasek R, Theorell T. Healthy work: stress, productivity and the reconstruction of working life. New York: Basic Books; 1990.

25. Alves MGM. Pressão no trabalho: estresse no trabalho e hipertensão arterial em mulheres no estudo Pró-saúde [tese]. Rio de Janeiro: Escola Nacional de Saúde Pública, Fundação Oswaldo Cruz; 2004.

26. Alves MGM, Chor D, Faerstein E, Lopes CS, Werneck G. Versão resumida da "job stress scale": adaptação para o português. Rev Saude Publica 2004; 38(2):164-171.
27. Victora CG, Huttly SR, Fuchs SC, Olinto MT. The role of conceptual frameworks in epidemiological analysis: a hierarchical approach. Int J Epidemiol 1997; 26(1):224-227.

28. Souza ER, Minayo MCS, Silva JG, Pires TO. Fatores associados ao sofrimento psíquico de policiais militares da cidade do Rio de Janeiro. No prelo, 2012.

29. Minayo MCS, Souza ER, Constantino P. Missão Proteger: condições de vida, trabalho e saúde dos policiais militares do Rio de Janeiro. Rio de Janeiro: Editora Fiocruz; 2008.

30. Souza ER, Minayo MCS. Policial, risco como profissão: morbimortalidade vinculada ao trabalho. Cien Saude Colet 2005; 10(4):917-928.

31. Andrade ER, Souza ER, Minayo MCS. Intervenção visando a auto-estima e qualidade de vida dos policiais civis do Rio de Janeiro. Cien Saude Colet 2009; 14(1):275-285.

32. Andrade ER, Souza ER. Autoestima como expressão de saúde mental e dispositivo de mudanças na cultura organizacional da polícia. Psicologia Clínica (PUCRJ. Impresso) 2011; 22:179-195.

33. Sennett R. O Artifice. Rio de Janeiro: Record; 2009.

34. Souza ER. Violência velada e revelada: estudo epidemiológico das causas externas em Duque de Caxias. Cad Saude Publica 1993; 9(1):48-64.

35. Rodrigues PF, Alvaro ALT, Rondina R. Sofrimento no trabalho na visão de Dejours. Revista Científica Eletrônica de Psicologia 2006; 4(7).

36. Freud S. A Interpretação dos Sonhos. Vol. V. Rio de Janeiro: Imago; 1969.

37. Lévi-Strauss C. Introdução à Obra de Marcel Mauss. Paris: PUF; 1950.

38. Vermeulen M, Mustard C. Gender differences in job strain, social support at work, and psychological distress. J Occup Health Psychol 2000; 5(4):428440.

39. Luz ES. Estudo do Estresse Ocupacional em Mulheres Policiais Militares da Cidade do Rio de Janeiro [dissertação]. Rio de Janeiro: Instituto Fernandes Figueira, Fundação Oswaldo Cruz; 2011.

40. Bezerra CM. Estresse Ocupacional Autoatribuido em Mulheres Policiais Militares da Cidade do Rio de Janeiro [dissertação]. Rio de Janeiro: Escola Nacional de Saúde Pública, Fundação Oswaldo Cruz; 2012.

41. Souza ER, Franco LG, Meireles CC, Ferreira VT, Santos NC. Sofrimento psíquico entre policiais civis: uma análise sob a ótica de gênero. Cad Saude Publica 2007; 23(1):105-114.

42. Dejours C. Uma visão do sofrimento humano nas organizações. In: Chanlat JF, organizador. $O$ indivíduo na organização: dimensões esquecidas. São Paulo: Atlas; 1996.

Artigo apresentado em 28/05/2012

Aprovado em 15/062012

Versão final apresentada em 05/07/2012 